\title{
The effect of a changed environment on bacterial colonization rates in an established burns centre
}

\author{
BY P. J. WORMALD \\ Public Health Laboratory, Odstock Hospital, Salisbury, Wilts
}

(Received 6 July 1970)

\begin{abstract}
SUMMARY
In an established burns centre which moved from an old building to new purpose-designed premises, colonization rates of patients' burns with Staphylococcus aureus, Pseudomonas aeruginosa and other Gram-negative bacilli were not reduced. Colonization rates with Streptococcus pyogenes increased but the increase was mainly due to multiple importations in the new premises of a strain of higher communicability than any seen in the old.

In the first 32 months in the new environment 10 patients were found colonized with pseudomonas on admission and 20 became colonized in the unit. A much higher proportion of patients with burns of more than $30 \%$ body surface became colonized than of patients with less. About one-third of the above 20 patients became colonized with strains already isolated from another patient; all but one of them had small area burns. Cross-infection was not observed from numerous heavily colonized patients with high percentage burns. This paradox is discussed in detail. Basin outflows in the new premises became colonized with $P$. aeruginosa of two serotypes not found on patients in this unit.
\end{abstract}

\section{INTRODUCTION}

The transfer of an established burns centre to a new purpose-designed building without change in the senior staff, the principles and practice of treatment, the range of patient intake and the frequency and technique of bacteriological monitoring enabled observation of the effect of an improved environment alone on the cross-infection rates. The old unit was housed in a war-time hutted building with a wide passage opening into four wards accommodating $7,3,3$ and 3 patients, a total of 16. There was no air-conditioning. The new unit is built on the race-track principle and has four double and thirteen single rooms, accommodating a total of 21 patients. It is fully air conditioned on a high-velocity dual duct system using $100 \%$ fresh air. Patients' rooms are under a positive pressure with ten inlet changes of air per hour and six extract changes. The treatment rooms are at a higher rate of twelve inlet and twelve extract changes. Average working temperatures are $68^{\circ} \mathrm{F}$. and average humidities $55 \%$. Air enters rooms at ceiling level near the perimeter wall above patients' beds and leaves partly through extract filters in toilets and partly through pressure relief grilles into the corridors whence it is extracted at high level. The object is to minimize the risk of air-borne infection 
to the patient by preventing air entry from passages to rooms. Repeated observations with titanium chloride smoke have not shown air-flow into patients' rooms even while opening their doors.

The régime in use from 1963, when detailed bacteriological records were started, was aimed specifically against the development of infection with Pseudomonas aeruginosa. It consisted of strict insistence on keeping burns dry, of minimal use of antibiotics, of exposure of burns in the early stages and of dressing in later stages with gauze squares impregnated with polyethylene glycol and $1 \%$ nitrofurazone. Because of its success under the conditions in this centre both in preventing invasive infection and in preparation for grafting, it has been practised with little or no variation until the present time.

The clinical consequences of colonization with Streptococcus pyogenes, Staphylococcus aureus or $P$. aeruginosa were generally slight. Colonization with Strep. pyogenes was often associated with characteristic erythema, exudate and pyrexia which responded rapidly to benzylpenicillin or phenoxymethyl penicillin. The frequent additional presence of pencillinase-producing staphylococci, though it may have prolonged surface carriage, did not appear to prejudice clinical effectiveness. Erythromycin was sometimes used in place of penicillin. Antibiotic treatment of staphylococci or pseudomonas was seldom required. Tetracycline, ampicillin, methicillin, cloxacillin, carbenicillin, parenteral or topical gentamycin, sulphamylon or silver nitrate were seldom used. Prophylactic penicillin or erythromycin were not routinely used. Data on the proportion of patients with extensive burns, on which colonization rates with pseudomonas are strongly dependent, are given in the appropriate section.

\section{METHODS}

Swabs were taken as soon as possible after admission from one or more areas of burn and were repeated weekly or as thought necessary for clinical reasons. Each swab was cultured on a tryptic digest blood agar plate with $2.5 \%$ agar. Single colonies from minority populations were subcultured either from zones of inhibition round antibiotic disks placed in the dense part of the inoculum or from the thin end of the spread, for identification by standard methods. Swarming of proteus was not a problem under these conditions. In the new unit nasal and throat swabs were cultured from patients on admission and from staff during periods of high streptococcal prevalence or on the appearance of a new strain of Strep. pyogenes other than an obvious importation.

Swabs from basin outflows for pseudomonas were inserted into the water traps a foot below the outlet. These and other environmental swabs were cultured on nutrient agar and in peptone water. Doubtful mixed growths were subcultured on $0.03 \%$ cetrimide agar.

Strains of Strep. pyogenes were serotyped at the Public Health Laboratory, Oxford, by T-agglutination and M-precipitation typing (Williams \& Maxted, 1953; Williams, 1958). Strains of P. aeuruginosa were typed at the Cross-Infection Laboratory, Colindale. Primary subdivision was by serological typing (Habs, 1958) with additions as specified in Lowbury et al. (1970). Individual serotypes were 
further subdivided by phage typing; strains were considered different only when phage typing patterns were quite distinct.

Air sampling was done by the Safety Section of the Microbiological Research Establishment, Porton.

\section{RESULTS}

\section{Air contamination rates}

Slit sampling was done at a rate of 1 cu.ft./min. and plates were incubated for $21 \mathrm{hr}$. at $37^{\circ} \mathrm{C}$. In the old unit $160 \mathrm{cu}$.ft. were sampled on four different occasions in the passages, yielding an average particle count of $14 / \mathrm{cu}$.ft. with a maximum of 78. Corresponding observations in the passages of the new unit on $110 \mathrm{cu}$.ft. on four occasions yielded an average particle count of $1 \cdot 6 / \mathrm{cu} . \mathrm{ft}$. with a maximum of 4.5. A further sample of $45 \mathrm{cu}$.ft. during electric polishing and other human activity yielded an average of seven particles/cu.ft., corresponding with the average aircontamination rate in a plenum ventilated theatre with much staff activity (Williams, Blowers, Garrod \& Shooter, 1966). During dressing sessions in a patient's room sampling yielded maximum counts of 27 particles/cu.ft. and in a treatment room of 16 particles/cu.ft. When activity ceased counts rapidly returned to minimum level. During a period of high streptococcal prevalence in the new unit 0.6 particles/cu.ft. of Strep. pyogenes was grown from air samples in the passages.

\section{Colonizations with Pseudomonas aeruginosa}

Analysis of cultures from patients were made in three periods, for 21 months in 1963-4, for 16 months in 1966-7 up to the time of transfer to the new environment and for the first 32 months in the new unit, 1967-9. The findings are shown in Table 1 from which it is evident that the rates in each period are strikingly constant both in the number of patients already colonized on arrival and in those whose colonizations developed after admission. There was no reduction in colonizations in the new environment.

Table 1. Comparison between the old and new units of patients with burns colonized by Pseudomonas aeruginosa

\begin{tabular}{lccrc} 
& & & \multicolumn{2}{c}{ Numbers colonized } \\
Old 1963-4 & Months & Patients & Imported & Developed in unit \\
Old 1966-7 & 21 & 208 & $6(2 \cdot 9 \%)$ & $11(5 \cdot 3 \%)$ \\
Total old & 16 & 154 & $5(3 \cdot 2 \%)$ & $11(7 \cdot 1 \%)$ \\
New 1967-70 & 37 & 362 & $11(3.0 \%)$ & $22(6.1 \%)$ \\
& 32 & 351 & $10(2.9 \%)$ & $20(5 \cdot 7 \%)$
\end{tabular}

Patients with extensive burns become colonized with pseudomonas much more often than those with smaller burnt areas. The 208 patients in the first period in the old unit (1963-4) and the 351 patients in the new unit (1967-9) were subdivided according to their percentage burns into three categories, $30 \%$ or more of body surface, $15-29$ and $14 \%$ or less, excluding those, mostly old people with very high percentage burns, who died within a week of admission, and those already colonized on arrival. The findings are shown in Table 2, and the figures show clearly that 
in terms of percentage burns, both the patient intake and the colonization rates were quite constant between 1963-4 in the old unit and 1967-9 in the new. They also show much higher colonization rates in patients with $30 \%$ or more burnt areas than in patients with less.

Table 2. Comparison of colonizations with Pseudomonas aeruginosa according to percentage body surface burnt, in three categories between a period of 21 months in 1963-4 in the old unit and 32 months in 1967-9 in the new

(Patients who were admitted already colonized or who died within 1 week of admission are excluded.)

$\begin{array}{llcc}\text { Burn category } & \begin{array}{c}\text { Environ- } \\ \text { ment }\end{array} & \text { Number of patients } & \begin{array}{c}\text { Number colonized } \\ \text { with } P \text {. aeruginosa }\end{array} \\ 30 \% \text { or over } & \text { Old } & 8(4 \% \text { of total }) & 3(38 \%) \\ & \text { New } & 18(5 \% \text { of total }) & 7(43 \%) \\ 15-29 \% & \text { Old } & 36(18 \% \text { of total }) & 4(11 \%) \\ & \text { New } & 58(17 \% \text { of total }) & 4(7 \%) \\ 14 \% \text { or under } & \text { Old } & 154(78 \% \text { of total }) & 4(3 \%) \\ & \text { New } & 259(78 \% \text { of total }) & 9(3 \%)\end{array}$

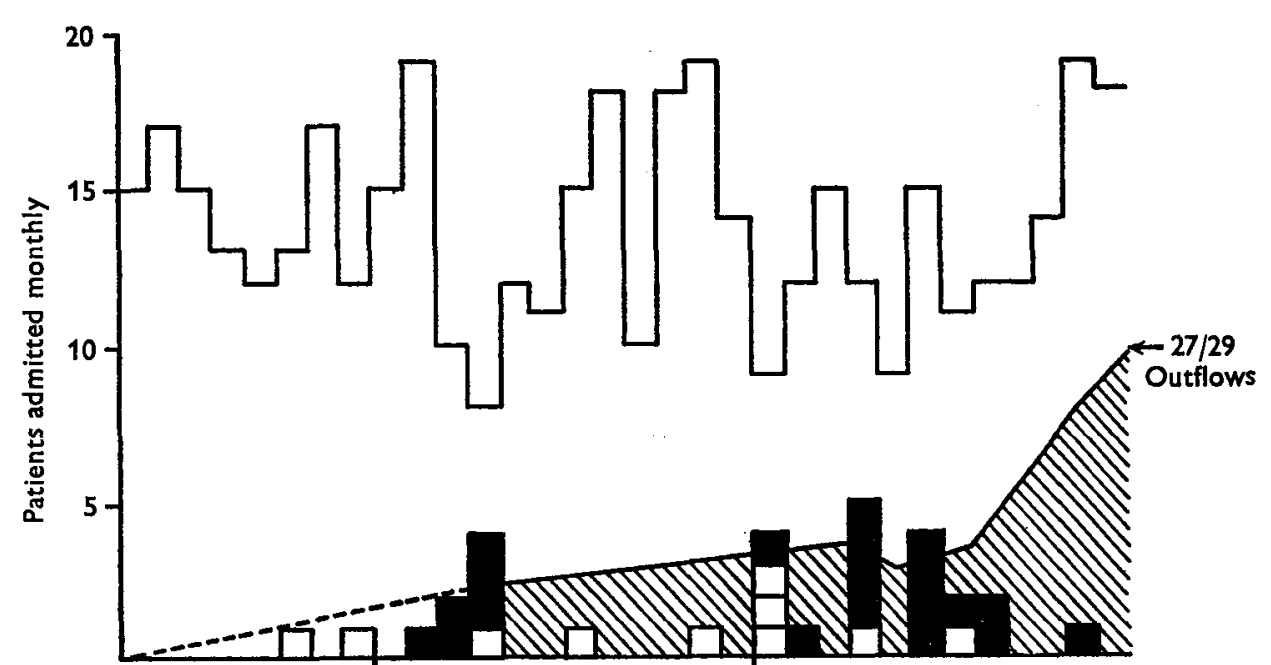

M. J. J. A. S.O.N.D. J. F.M. A.M. J. J.A. S.O.N.D. J. F.M.A.M. J. J. A.S.O.N.D. 1967 1968 1969

Fig. 1. New unit-first 32 months. $\square$, Colonization with $P$. aeruginosa imported on burns (10 patients);, , colonization with $P$. aeruginosa developing after admission (20 patients). Shaded area shows proportion of 29 basin and bath outflows colonized with $P$. aeruginosa.

Analysis of strains from patients in the new unit

Colonizations with $P$. aeruginosa in the first 32 months in the new unit were few enough to attempt to trace the source and spread of each type. If the 30 colonizations, 10 imported and 20 developing after admission, are plotted chronologically (Fig. 1) the latter are seen to be clustered in groups, six in February-April 1968, six in January-April 1969, seven in June-August 1969 and a single one in November 
1969. These groups may be considered as separate incidents. Typing of the strains and other details are shown in Table 3.

Patients 3-8. Patient 1 had a different serotype to any of these six and patient 2, whose strain was not typed, had been discharged 12 days before patient 3 became colonized. Patient 5 was sharing a double room with patient 4 and was undoubtedly cross-infected from him. Patient 7 though not in direct contact with patient 6 shared an identical strain. Judged by phage patterns and serotypes, therefore, four patients were infected with different strains and the other two may be considered as cases of cross-infection.

Table 3. Types of Pseudomonas aeruginosa colonizing the burns of 30 patients in the first 32 months in the new unit

(Markedly different phage patterns are each represented by a letter as an aid to clarity. $\mathrm{NT}^{\top} \mathrm{T}=$ not tested.)

\begin{tabular}{|c|c|c|c|c|c|}
\hline $\begin{array}{l}\text { Patient's } \\
\text { number }\end{array}$ & $\begin{array}{l}\text { Date first } \\
\text { cultured }\end{array}$ & $\begin{array}{l}\text { Days after } \\
\text { admission }\end{array}$ & $\begin{array}{l}\text { Weeks } \\
\text { cultured }\end{array}$ & $\begin{array}{l}\text { Phage } \\
\text { pattern }\end{array}$ & Serotype \\
\hline $\mathbf{l}$ & 9. x. 67 & Imported & 2 & $\mathbf{A}$ & 11 \\
\hline 2 & 28. xii. 67 & Imported & 5 & NT & $\mathrm{NT}$ \\
\hline 3 & 12. ii. 68 & 15 & 5 & B & 6 \\
\hline 4 & 9. iii. 68 & 9 & 3 & C & 6 \\
\hline 5 & 30. iii. 68 & 64 & 4 & C & 6 \\
\hline 6 & 1. iv. 68 & 10 & 1 & D & $2 B$ \\
\hline 7 & 20.iv. 68 & 35 & 2 & $\mathbf{D}$ & $2 \mathrm{~B}$ \\
\hline 8 & 24. iv. 68 & 5 & 2 & $\mathbf{E}$ & $5 \mathrm{C}$ \\
\hline 9 & 29. iv. 68 & Imported & 1 & $\mathrm{~B}^{1}$ & 6 \\
\hline 10 & 15. vii. 68 & Imported & 3 & $\mathbf{F}$ & 10 \\
\hline 11 & 30. xi. 68 & Imported & 2 & $\mathrm{G}$ & 4 \\
\hline 12 & 8. i. 69 & Imported & $\mathbf{l}$ & $\mathrm{H}$ & 11 \\
\hline 13 & 9. i. 69 & Imported & 1 & $\mathbf{H}$ & 11 \\
\hline 14 & 20. i. 69 & Imported & 3 & $\mathrm{~N}^{\prime} \mathrm{T}$ & NT \\
\hline 15 & 26. i. 69 & 31 & 2 & $J$ & 3 \\
\hline 16 & 8. ii. 69 & 8 & 16 & $\mathbf{K}$ & 6 \\
\hline & 2. vi. 69 & & & L & 8 \\
\hline$\overline{17}$ & 14. iv. 69 & 17 & 4 & $\mathrm{M}$ & 6 \\
\hline 18 & 24. iv. 69 & 32 & 5 & $\mathbf{M}$ & 6 \\
\hline$\overline{19}$ & 14. iv. 69 & Imported & 2 & $\mathbf{L}$ & 8 \\
\hline 20 & 17. iv. 69 & 2 & 7 & $\mathbf{N}$ & 6 \\
\hline 21 & 26. iv. 69 & 19 & 1 & $\mathrm{O}$ & $5 \mathrm{D}$ \\
\hline 22 & 12. vi. 69 & 3 & 6 & $\mathbf{P}$ & $5 \mathrm{C}$ \\
\hline 23 & 23. vi. 69 & 14 & 3 & $\mathrm{Q}$ & - \\
\hline 24 & 25. vi. 69 & 16 & 4 & $\mathrm{R}$ & 3 \\
\hline 25 & 28. vi. 69 & 3 & 1 & $\mathbf{S}$ & $5 \mathrm{C}$ \\
\hline 26 & 28. vii. 69 & Imported & 5 & $\mathrm{~T}$ & II \\
\hline 27 & 3. viii. 69 & 5 & 2 & $\mathrm{C}$ & 6 \\
\hline 28 & 5. ix. 69 & 23 & 1 & $\mathrm{~T}^{\mathbf{1}}$ & 11 \\
\hline 29 & 14. ix. 69 & 27 & 1 & $\mathrm{~T}$ & 11 \\
\hline$\overline{30}$ & 24. xi. 69 & 24 & 1 & $\mathrm{U}$ & 3 \\
\hline
\end{tabular}

Patients 15-18, 20 and 21. The strain from patient 14 was not typed but it shared a characteristically deep pigment with that from patient 15 and could have been the same. No source was evident for the strains on patients 16 and 17. Patient 18 was probably cross-infected from patient 17 . The second strain isolated late from 
patient 16 could have been derived from the strain imported on patient 19 . The up-growth on patient 20 of the common serotype 6 as early as the second day is more consistent with carriage before arrival than of cross-infection from the strain of patient 16, the phage pattern of which might have undergone alteration after 10 weeks carriage. The strain infecting patient 21 had not been seen before. In this group there appear to have been three, perhaps four instances of crossinfection.

Patients 22-25, 27, 28 and 29. Patients 22-24 were among four North Africans burnt in an oil refinery accident, flown to England and admitted to the unit together. It is notable that these three whose burns became colonized with pseudomonas on the 3rd, 14th and 16th days were each infected with one of three unrelated strains. They are considered in more detail in the discussion. Patient 25 was colonized when patient 22 had been infected with the same serotype for 16 days, but the phage patterns were quite distinct. No source was evident for patient 27 . The strain from patient 29 was identical with the imported strain from patient 26 and the strain from patient 28 might have been a variant from it. In this group there were one probable and two possible instances of cross-infection.

Patient 30. No source was evident.

Thus five pairs of strains from different patients were identical and one almost identical in phage pattern and serotype and a few with the same serotypes had minor differences in phage patterns. So far as conclusions can be drawn from these limited data, about one-third of the 20 patients who became colonized in the unit were cross-infected from other patients.

Patients, 4, 6, 14, 17 and 19 (Table 3) from each of whom another patient was thought to be cross-infected, had burnt areas of only $9,7,10,8$ and $5 \%$ respectively. Only patient 26 among the six who might have been the source of cross-infection of another patient, had extensive burns (44\%). Patients 7, 16, 18, 20, 22, 23 and 30 , with burns of $45,65,40,65,42,65$ and $40 \%$ respectively, though needing much closer and more prolonged attention from nursing staff and, presumably, shedding far more pseudomonas, do not appear to have caused cross-infection of other patients. Patient 4 was sharing a double room with patient 5 who later became colonized with the same strain; patients $6,14,17$ and 19 were all very elderly and almost immobile, they could not therefore have transmitted their strains by personal mobility in the unit. The apparent anomaly that cross-infection was not seen from patients with the heaviest colonizations of pseudomonas is considered in the discussion.

\section{Analysis of strains from basin outflows}

The common presence of $P$. aeruginosa in water traps below sinks, sluices and bath outflows in hospitals has long been believed to be a cross-infection hazard and an association between types in sinks and burns has been reported (Kohn, 1966). In the new burns unit there are 29 outflows from sinks and baths. These were not swabbed when the unit was first opened. In May 1968 after a year's working P. aeruginosa was isolated from 7 of them and in April 1969 after 2 year's working, from 11. For the next 3 months positive outflows were treated with a 
caustic powder flushed down with boiling water, which sterilized them temporarily after each application. This experimental practice was stopped in August 1969 because on comparing types isolated from patients' burns with types isolated from sink units in their rooms it seemed elear that patients were seldom, if ever, infected from this source, an observation in agreement with that reported by Jellard \& Churcher (1967) from a premature baby unit and by Lowbury et al. (1970) in a study on pseudomonas infection in patients with tracheostomy. Subsequently the number of infected outflows rapidly increased to 18 in October 1969, 24 in November 1969 and 27 in January 1970. These findings are shown in Fig. 1.

Table 4. Serotypes of Pseudomonas aeruginosa recovered from basin outflows in relation to serotypes recovered from patients (New Unit, May 1968 to October 1969. UT = Untypable.)

$\begin{array}{cccccc}\text { Serotype } & \begin{array}{c}\text { Number of } \\ \text { strains }\end{array} & \begin{array}{c}\text { Number of } \\ \text { outflows }\end{array} & \text { Imported } & \begin{array}{c}\text { Developed } \\ \text { in unit }\end{array} & \begin{array}{c}\text { Strain in room } \\ \text { related to } \\ \text { patient }\end{array} \\ 1 & 13 & 8 & 0 & 0 & - \\ 4 & 3 & 3 & 1 & 0 & - \\ 9 & 6 & 6 & 0 & 0 & - \\ 10 & 21 & 15 & 0 & 0 & - \\ 13 & 1 & 1 & 0 & 0 & - \\ \text { UT } & 2 & 2 & 0 & 1 & 2 \\ 6 & 3 & 3 & 1 & 8 & 1 \\ 11 & 5 & 4 & 4 & 2 & 1 \\ 5 \mathrm{C} & 1 & 1 & 1 & 1 & 1 \\ 5 \mathrm{D} & 1 & 1 & 0 & 1 & -\end{array}$

Up to October 1969, 56 strains grown from outflows were typed. Distribution according to serotype is shown in Table 4. In four of the five strains associated with patients colonized with the same type the outflow was probably infected from the patient. By far the greatest number of isolations were of serotypes 1, 9 and 10 . Serotypes 1 and 9 were not isolated from any patient in this unit; serotype 10 was isolated once, imported on a patient in July 1968.

In November 1969 basins in six rooms were selected for more intensive study. From each positive primary culture a typical colony at the end of the spread representing the predominant strain was subcultured for typing and also any other colonies showing morphological differences. Table 5 shows the serotypes recovered from these outflows. The transient presence of serotype 6 in rooms $B$ and $\mathrm{E}$ followed the residence of patients colonized with type 6 in each. The presence of serotype 11 for 2 months in room $C$ followed the residence of a patient colonized with type 11 in that room. The transient presence of serotype $5 \mathrm{D}$ in the basin outflow in the treatment room $\mathrm{D}$ preceded colonization with type $5 \mathrm{D}$ on a patient who had been dressed in that treatment room. The rare serotype 13, not found on any patient, was recovered once in May 1969 from room $C$ and once from room B 8 months later. Serotype 1, not found on any patient, and serotype 10, imported once on a patient, gained almost undisputed possession of this environment. 


\section{Colonizations with Gram-negative bacilli other than pseudomonas}

These organisms consisted chiefly of strains of Escherichia coli and Proteus spp. Klebsiella aerogenes, though often isolated from other parts of the hospital, was not often found colonizing burns. In 1963-4, in 21 months in the old environment, burns on $39 / 208(19 \%)$ patients, of whom eight also harboured $P$. aeruginosa, were found colonized at some time. In 1967-9, in the first 30 months in the new environment, burns on $79 / 320(25 \%)$ patients, of whom 13 also harboured $P$. aeruginosa, were found colonized at some time.

Table 5. Serotypes of Pseudomonas aeruginosa recovered from selected basin outflows

$\begin{array}{cccccccccc}\text { Room } & 9 . \mathrm{iv} . & 14 . \mathrm{v} & 28 . \mathrm{ix} . & 10 . \mathrm{ix} . & 7 . \mathrm{xi} . & 13 . \mathrm{xi} & 17 . \mathrm{xi} . & 27 . \mathrm{xi} . & 7 . \mathrm{i} .70 \\ \text { A } & 10 & - & 10 & 10 & 1 & 1,10 & 1,10 & 1,10 & 1,10 \\ \text { B } & - & 6 & 10 & 10 & 10 & 10 & 10 & 10 & 1,13 \\ \text { C } & 6 & 13 & - & 11 & 11 & 10 & 11 & 10 & 10 \\ \text { D } & 5 \mathrm{D} & - & - & - & 1,10 & - & 1,10 & 1,10 & - \\ \text { E } & 10 & \text { UT } & - & 6 & 1,10 & 1,10 & 1,10 & 10 & 1,10 \\ \text { F } & 10 & 9 & 1 & 1 & 1 & 1 & 1 & 1 & 1\end{array}$

Table 6. Numbers of patients annually with burns colonized by Streptococcus pyogenes

$\begin{array}{lrrrrrrr} & 1963 & 1964 & 1965 & 1966 & 1967 & 1968 & 1969 \\ \text { Patients } & 128 & 161 & 147 & 137 & 170 & 169 & 160 \\ \begin{array}{l}\text { Colonized with Strep. } \\ \begin{array}{l}\text { pyogenes } \\ \text { Percentage }\end{array}\end{array} & 25 & 27 & 43 & 40 & 51 & 71 & 55 \\ & 20 & 17 & 29 & 29 & 30 & 42 & 34\end{array}$

Colonizations with Streptococcus pyogenes

The régime which is believed to have kept colonizations with $P$. aeruginosa at a reasonably low level for the past 7 years was much less successful in preventing colonizations with Strep. pyogenes. Table 6 shows, for each of the 7 years 1963-9, the numbers of patients from whom swabs were cultured and the numbers who harboured Strep. pyogenes in their burns at some time. The infection rate rose sharply in the new unit, one reason for which became apparent on observation of the behaviour of individual strains after importation.

Analysis of streptococcal types isolated from patients and the numbers of patients colonized with each, for the last 52 months in the old environment and the first 27 months in the new, is shown in Table 7. The comparison is not quite exact because typing records were available for only $65 \%$ of the strains isolated in the old unit and for over $90 \%$ in the new. However, it is clear, both from the variety of serotypes and from observing multiple introductions of the same type at different times, that importations of streptococci were very common in both environments.

Some types that were repeatedly imported did not spread, others were seen to spread only to a limited extent and a few caused epidemics of cross-infection. For the purpose of this study a strain was considered to cause an epidemic when, after 
importation, it resulted in cross-infection of six or more patients. Eight such 'epidemics' are shown in Table 8, six of which occurred in the first 27 months in the new environment and only two in twice that length of time in the old. It is, however, plain from the 12 cross-infections caused by the strain of type 24 that epidemic spread could occur in the old environment as well as in the new. The most striking difference is in the 44 patients cross-infected by type 4 during three

Table 7. Serotypes of Streptococcus pyogenes colonizing patients in the last 52 months in the old unit and the first 27 months in the new

(TNF $=$ Type not found. Figures in brackets = number of patients.)

\begin{tabular}{|c|c|c|c|c|c|c|c|}
\hline \multirow[b]{2}{*}{ M type } & \multirow[b]{2}{*}{$\mathrm{T}$ pattern } & \multicolumn{3}{|c|}{ Number of patients } & \multicolumn{3}{|c|}{ Number of patients } \\
\hline & & $\begin{array}{l}\text { Old } \\
\text { unit }\end{array}$ & $\begin{array}{l}\text { New } \\
\text { unit }\end{array}$ & M type & T pattern & $\begin{array}{l}\text { Old } \\
\text { unit }\end{array}$ & $\begin{array}{l}\text { New } \\
\text { unit }\end{array}$ \\
\hline 1 & 1 & 1 & 7 & $2(2)$ & $2(4)$ & 4 & - \\
\hline Not tested & 4 & 2 & 54 & TNF & 3 & 3 & 2 \\
\hline 12 & 12 & - & 19 & $5(2)$ & $5 / 27(3)$ & 3 & - \\
\hline TNF & 12 & 4 & 11 & $6(1)$ & $6(3)$ & l & 2 \\
\hline 24 & $4 / 28$ & 18 & - & $9(1)$ & $9(3)$ & - & 3 \\
\hline 28 (R type) & $28,4 / 28$ & 9 & 8 & TNF & $11,3 / 11$ & 8 & - \\
\hline TNF & $28,4 / 28$ & 7 & 6 & $\mathrm{TNF}$ & 14 & 1 & 1 \\
\hline $22(1)$ & $22(9)$ & 9 & - & 17 & $17 / 22 / 47$ & 1 & - \\
\hline TNF & $3 / \mathrm{B} 3264$ & 6 & 9 & TNF & 18 & 2 & - \\
\hline TNF & $\begin{array}{l}8 / 15 / 25 / \operatorname{Imp} 19 \\
\text { and variants }\end{array}$ & 6 & 10 & - & - & - & - \\
\hline
\end{tabular}

Table 8. Epidemics of cross-infection with individual types of Streptococcus pyogenes following single importations

$(\mathrm{TNF}=$ Type not found. NT $=$ Not tested.)

\begin{tabular}{|c|c|c|c|}
\hline \multirow[b]{2}{*}{ M type } & \multirow[b]{2}{*}{$\mathrm{T}$ pattern } & \multicolumn{2}{|c|}{ Patients cross-infected } \\
\hline & & Old unit & New unit \\
\hline NT & 4 & - & 25 \\
\hline 12 & 12 & - & 14 \\
\hline 24 & $4 / 28$ & 12 & - \\
\hline $\mathrm{NT}$ & 4 & - & 10 \\
\hline $\mathrm{NT}$ & 4 & - & 9 \\
\hline 1 & 1 & - & 7 \\
\hline $28(\mathrm{R})$ & $4 / 28$ & - & 7 \\
\hline \multirow[t]{2}{*}{ TNF } & 22 & 6 & - \\
\hline & & Is $\quad 18$ & 72 \\
\hline
\end{tabular}

importations into the new unit; only two isolations of type 4 were recorded in the old. During the episodes of type 4 cross-infection, nasal and throat swabs taken repeatedly from the staff only once yielded a positive result, from a throat swab. On the other hand, the strain of type 1 which caused cross-infection of seven patients was imported by a member of the nursing staff with pharyngitis. It then caused pharyngitis in five other nurses who clearly could have infected patients before they could be removed from duty. Hence the apparently high communic- 
ability of strains of type 4 in the new unit owed nothing to naso-pharyngeal infection among the staff and could account for most of the increased streptococcal colonization rate. The further possibility that conditions in the new environment somehow favoured streptococcal shedding and spread is considered in the discussion.

\section{Colonizations with Staphylococcus aureus}

Between 1961 and 1967, 357 strains of penicillinase-producing Staph. aureus from burn cultures were phage typed. Predominant phage patterns occurred in the chronological order $52 / 52 \mathrm{~A} / 80 / 81,80 / 81,77,80 / 81,85$ and $52 / 52 \mathrm{~A} / 80 / 81$. Other more heterogeneous Group III patterns were also prevalent in 1961-2 and 1965-7 and, probably, an untypable strain in 1964-5.

In 1963-4, in 21 months in the old environment, burns on 166/208 (80\%) patients were found colonized with Staph. aureus at some time; 100/166 (60\%) staphylococcus-colonized patients were shown to carry penicillinase-producers. In 1967-9 in the first 30 months in the new environment, $271 / 320(85 \%)$ patients were found colonized with Staph. aureus; $231 / 271$ (85\%) staphylococcus-colonized patients were shown to carry penicillinase-producers. Thus, the proportion of patients colonized with penicillinase-producers rose from 60 to $85 \%$. In these two periods $42(18 \%)$ and $164(36 \%)$ patients were colonized with Strep. pyogenes. Those from whom Strep. pyogenes and penicillinase-producing staphylococci were at some time isolated from the same swab were $20(10 \%$ of patients) and $107(33 \%$ of patients).

\section{DISCUSSION}

The new environment did not reduce colonization rates of patients with Strep. pyogenes, Staph. aureus, P. aeruginosa or other Gram-negative bacilli. Indeed the streptococcal infection rates rose sharply though reasons have been given for believing that this was due to the presence of strains of increased communicability. Yet two features peculiar to the new unit may more than counterbalance the effect of the improved segregation of patients and protection in their rooms from airborne infection. The continuous movement of air in the new unit was observed clinically to effect more satisfactory surface drying; perhaps this resulted in increased streptococcal shedding from eschars. The continuous flow of air from above a patient's bed, perceptible to anyone who stands there, may be expected to carry infected particles from burn eschars directly against the persons of staff performing dressings and also into the passages. Transfer of such particles by staff was prevented as far as possible by changing gowns between one room and the next. However, some patients who had not left their rooms since admission became cross-infected with streptococci. During a wave of infection with Strep. pyogenes type 4, this organism was grown from swabs from floors, other surfaces, curtains and toys in a room occupied by a child shedding it, and also from stored skin from this child. In the passages outside such infected rooms an average of $0 \cdot 6$ airborne particles of Strep. pyogenes/cu.ft. was found by slit-sampling. It was also recovered on one occasion from the hair of three out of six nurses who had been in contact 
with infected patients. Clearly, direct contact with staff was the most likely means whereby such patients became cross-infected with streptococci.

Staphylococci and streptococci are shed from colonized burns in far larger quantities than from any other source. Counts by the agar sausage method (Ten Cate, 1965) showed little difference between the old and the new units but equilibrium levels on various floor surfaces in both carried six to twenty times as many staphylococcal particles as corresponding surfaces in medical and surgical wards in the same hospital. Ayliffe et al. (1967) showed that fall-out bacteria on floors do not readily become redispersed but it is reasonable to assume that the staphylococcal equilibrium level on a floor is a fair measure of the numbers that have been shed and were once airborne. The increase in proportion of penicillinase-producing staphylococci from $60 \%$ of patients in 1963-4 to $85 \%$ of patients in 1967-9 may be the result of the continuous selective pressure maintained by treating streptococcal infections with penicillin, and the common presence of penicillinaseproducing staphylococci with Strep. pyogenes may have prolonged surface carriage of streptococci and contributed to the rather high streptococcal colonization rates.

The high-rate of colonization with Gram-positive cocci contrasts with the low prevalence of $P$. aeruginosa. The observations of Govan \& Gillies (1969) on pyocine typing of multiple single colonies from patients' lesions lend some support to the belief that all or nearly all of the pseudomonas colonizations listed in Table 3 were single strain infections, at least in the early stages. No less than nine different serotypes (and within serotypes numerous differences in phage pattern) were seen among the strains from the 30 patients shown to be colonized with pseudomonas in the first 32 months in the new unit, showing the frequency of importation of unrelated strains. Although the survival time for pseudomonas in air is short Barclay \& Dexter (1968) found in another new burns centre that when the infection rate was high settle plates showed contamination with pseudomonas at heights all the way up to the ceiling. In this unit direct airborne spread from one room to another can be discounted. Yet even though the general degree of colonization was low, about one-third of the 20 patients developing colonizations in the unit appear to have been infected from another patient.

The origin of the infections of the other two-thirds of the 20 patients who were colonized with strains of pseudomonas not previously seen in the unit or apparently not present at that time is more debatable. No patients became colonized from the many basin outflows heavily infected with serotypes 1 and 10 and patientcolonizations with pseudomonas were at a minimum during the last 4 months of 1969 when nearly every outflow became contaminated with it and also during the first 5 months of 1970. On five occasions the strain from a colonized patient was recovered transiently from the basin outflow in the corresponding room, but only in one instance did the timing of isolations indicate that the outflow was colonized before the patient.

Had it been practicable to type multiple single colony subcultures of serial swabs from patients colonized with pseudomonas, mixed infections with minority populations might have been revealed; and had swabs been cultured from fluid medium, scanty growths would probably have been shown in some patients 
recorded as free from pseudomonas. However, such minor sources are quantitatively negligible compared with the massive shedding from patients with high percentage burns colonized with identified strains of pseudomonas, from whom cross-infection was not observed. Lowbury \& Fox (1954) showed that the hands of nurses in a burns unit were often contaminated with pseudomonas and Lowbury et al. (1970) showed that strains of pseudomonas infecting patients with tracheostomy were often isolated from the hands of nurses, physiotherapists and other staff. Hand swabs were not taken in this study but pseudomonas from heavily infected patients was likely to be present on hands of staff from time to time. Streptococcal and staphylococcal cross-infection was certainly transmitted by staff; why, therefore, was cross-infection with pseudomonas not seen from the very patients most heavily colonized?

The four North Africans, each nursed and dressed in a separate room from which he did not emerge for a fortnight, were all shown to become rapidly cross-infected with penicillinase-producing staphylococci and also with Strep. pyogenes type 12, the prevalent strain at that time. Three also became colonized with pseudomonas, each with a different type, on the 3rd, 14th and 16th days at a time when no other patient was colonized with pseudomonas and none of these three types were grown from other environmental sources. Perhaps these patients had no previous experience of such organisms and were specially host-receptive to minimal contamination from undisclosed sources. Pseudomonas appeared first on chest, back and neck respectively, not on 'pyoprone' (i.e. bathing-trunk) areas (Sachs \& Watson, 1969), a point against self-infection from the bowel. This, however, remains a possibility and in one series, $P$. aeruginosa was found in the faeces of nearly a quarter of patients on admission to hospital (Shooter et al. 1966).

Of the other patients, two were colonized on fresh grafting sites, one was colonized with a strain previously found in the sink outflow in the treatment room where he was dressed, three had been treated in other hospitals for more than a week and had moist eschars on admission and one had blisters stripped elsewhere before admission. The balance of evidence, therefore, suggests crossinfection as the most common source of colonization with strong differences in host receptiveness to account for the capricious absence of observed cross-infection from the most heavily colonized patients.

The many contaminations in basin outflows with strains of serotypes 1 and 10 suggest multiple infections from a common source. Recovery of serotype 9 from six basin outflows on one occasion only and of serotype 4 from three basin outflows on one occasion only, also suggests contamination from a common source. In these basins hollow tubed plugs replace overflow ducts and metal bulbs below rightangled bends replace U-traps. Each waste pipe then passes vertically through the floor into the top of a sloping 4-in. metal drain pipe, bacterial contamination from which is very unlikely. Water in the outflow traps remains uninfected so long as the rooms remain unused. In occupied rooms bacterially contaminated material regularly disposed of in basins included tooth water, washing water from nonburnt parts of patients' bodies and water from cloths (individual to each room) after wiping down surfaces. A separate floor mop was used for each room and the 
cleaning staff had orders not to raise mop heads above patients' floor surfaces. Pseudomonas was sought in floor mops, room cloths, flannels, toilet bowls, liquid soap dispensers, peppermint water, water taps and water samples. Strains of serotypes, 2, 3, 10 and 11 but not 1 were recovered from mop heads but the reason for the abundance of types 1 and 10 in outflows remains obscure unless the environment specially favoured colonization from minimal unobserved contaminations with these types.

I thank Mr J. Laing, Director, Mr D. C. McNeill, Sister J. Harvey, Sister J. Cotterell and other members of the staff of the Wessex Regional Burns Unit for unstinted help and facilities over many years, Dr M. T. Parker and Mrs D. Martin for typing strains of pseudomonas, Dr W. H. H. Jebb and Mr F. C. Saunders for typing strains of streptococci, Dr G. Thomas and Mr C. M. R. Pitman for undertaking slit-sampling and $\mathrm{Mr}$ C. Dowding for much technical help. I am also grateful to Dr E. J. L. Lowbury and to Dr M. T. Parker for valuable discussions.

\section{REFERENCES}

Ayliffe, G. A. J., Collins, B. J., Lowbury, E. J. L., BabB, J. R. \& Lilly, H. A. (1967). Ward floors and other surfaces as reservoirs of hospital infection. Journal of Hygiene 65, 515.

Barclay, T. L. \& Dexter, F. (1968). Infection and cross-infection in a new burns centre. British Journal of Surgery 55, 197.

Govan, J.R. W. \& Gillies, R. R. (1969). Progress in pyocine typing. Journal of Medical Microbiology $2,17$.

HABs, I. (1957). Untersuchungen über die O-Antigene von Pseudomonas aeruginosa. Zeitschrift für Hygiene und Infektionskrankheiten 144, 218.

Jellakd, C. H. \& Churcher, G. M. (1967). An outbreak of Pseudomonas aeruginosa (pyocyanea) infection in a Premature Baby Unit, with observations on the intestinal carriage of Pseudomonas aeruginosa in the newborn. Journal of Hygiene 65, 219.

Lowbury, E.J.L. \& Fox, J. (1954). The epidemiology of infection with Pseudomonas pyocyanea in a Burns Unit. Journal of Hygiene 52, 403.

Lowbury, E. J. L., Thoм, B. T., Lilly, H. A., Baвb, J. R. \& WhitTal, K. (1970). Sources of infection with Pseudomonas aeruginosa in patients with tracheostomy. Journal of Medical Microbiology 3, 39.

Кон,, J. (1966). In Research on Burns, Ed. A. B. Wallace and A. W. Wilkinson, p. 486. Edinburgh and London.

SAchs, A. \& Watson, J. (1969). Four years experience at a specialized burns centre. Lancet i, 718.

Shooter, R. A., Walker, K. A., Williams, V. R., HorgaN, G. M., Parker, M. T., Asheshov, E. H. \& Bullimore, J.F. (1966). Faecal carriage of Pseudomonas aeruginosa in hospital patients. Lancet ii, 1331.

Ten Cate, L. (1965). A note on a simple and rapid method of bacteriological sampling by means of agar sausages. Journal of Applied Bacteriology 28, 221.

Williams, R. E. O. (1958). Laboratory diagnosis of streptococcal infections. Bulletin of the World Health Organization 19, 153.

Wimltams, R. E. O., Blowers, B., Garrod, L. P. \& Shooter, R. A. (1966). Hospital Infection, 2nd Ed., 97. London: Lloyd-Luke.

Williams, R. E. O. \& Maxted, W. R. (1953). The type classification of Streptococcus pyogenes. Proceedings of the 6th International Congress of Microbiology 1, 46. 